\title{
Impact of Dynamic Pricing Strategies on Consumer Behavior
}

\author{
Amirreza Rohani (Corresponding author) \\ Faculty of Management, University of Tehran, Tehran, Iran \\ Tel: 98-912-283-0995E-mail: arohani.ie@gmail.com \\ Mohsen Nazari \\ Faculty of Management, University of Tehran, Tehran, Iran \\ E-mail: Mohsen.Nazari@ut.ac.ir
}

Received: June 27, 2012

Accepted: August 12, 2012

Published: October 1, 2012

doi:10.5296/jmr.v4i4.2009

URL: http://dx.doi.org/10.5296/jmr.v4i4.2009

\begin{abstract}
While hotels come up with various discount strategies to attract consumers, especially during a recession, both hotels and consumers seem to favor dynamic pricing. Yet there are not enough studies available to reveal that dynamic pricing would positively impact consumers. Studies also indicated that price discounts give consumers not only monetary benefits but also positive responses. The purpose of this study was to investigate how uniform pricing and dynamic pricing influence consumers behavior, in the presence of low involvement and high involvement consumers. The results of study suggested that high involvement consumers responded more positively to dynamic pricing than uniform pricing. Moreover, younger and female consumers are more likely to be involved in obtaining a discount, and high involvement consumers showed more positive feelings, and were more likely to tell others and make repeat purchases from a discount as compared to low involvement consumers.
\end{abstract}

Keywords: Consumer behavior, Consumer involvement, Dynamic pricing, Uniform pricing 


\section{Introduction}

Since the economic downturn has heavily affected the hotel industry, hotels have made various discount strategies available in order to attract consumers. It is a well known practice that during tough economic times hotels drop prices to stimulate demand against competitors (Enz, Canina and Lomanno, 2009) and to create the best cash flow possible in the short turn (Kimes, 2009). Among different pricing strategies, however, companies tend to favor dynamic pricing, and consumers seem to accept dynamic pricing. From a company's perspective, appropriately applied dynamic pricing will increase revenues and profits (Sahay, 2007). The success of dynamic pricing relies on the ability to segment consumers into different groups with different levels of willingness to pay (Dimicco, Maes and Greenwald, 2003). In particular, the hospitality and airline industries have increasingly employed dynamic pricing since their inventories are perishable, demand can be segmented, the products or services are sold well in advance, and demand fluctuates substantially (Kimes, 1989).

Despite the increased interest in dynamic pricing, limited studies are available to reveal that consumers would react positively toward dynamic pricing. From consumers' perspective, consumers seem to accept the application of dynamic pricing where they are charged different prices for the same service or product (Choi and Mattila, 2009; Kimes, 2002) since dynamic pricing enables consumers to make a choice over the price. Dynamic pricing has been used as a tool to provide price promotion; for example, consumers receive discounted rates if they accept restrictions, or if they make reservations in advance (Kimes, 2002). In addition, studies have showed that consumers react differently toward price discounts of the same products or services (Campo and Yague, 2007; Kimes, 2002). The concept of consumer involvement plays a significant moderating role. Baker, Cronin, and Hopkins (2009) noted that involvement can be used to segment consumers into low, moderate, and high involvement groups which encourages different promotional strategies. Thus, the different involvement a consumer attributes to a discount may not be independent from a consumer's preference on pricing strategies. Also, the involvement level may influence a consumer's discount receiving behavior, such as high involvement consumers demonstrating more positive feelings from obtaining a discount.

Despite the popularity of dynamic pricing in the hotel industry, there have been limited studies that examine the impact of dynamic pricing on consumer emotions and behaviors. So, the purpose of this study is to examine how discount strategies, dynamic and uniform, influence consumers' perspectives; particularly, their emotions and behaviors in the hotel industry in the presence of high and low involvement consumers. In the current study, dynamic and uniform pricing strategies are compared in order to identify which discount strategy consumers prefer. Emotions and behaviors of consumers are investigated how consumers respond to dynamic and uniform discount situations.

\section{Literature Review}

\subsection{Uniform Pricing \& Dynamic Pricing}

Sahay (2007) noted that most companies use comparatively simple strategies to determine 
prices: uniform pricing, competitive pricing, or cost-plus pricing. In uniform pricing, companies let prices remain uniform over time, regardless of the changes in the environment (Farahmand and Chatterjee, 2008). In competitive pricing, companies set prices based on their competitors' prices (Enz et al., 2009; Sahay, 2007) while companies with cost-plus pricing calculate the cost of a good or service and then add a profit margin (Sahay, 2007).

Uniform pricing lets companies have a fixed price over time, regardless of the changes in the environment and in the inventory level (Farahmand and Chatterjee, 2008), while competitive pricing allows companies to adjust their prices to competitors' prices (Enz et al., 2009; Sahay, 2007).

Traditionally, uniform prices would be set in the summer and be applied for the next entire year in a hotel; for example, hotels set a price in August or September for the following year. Uniform pricing requires hotels to commit to prices upfront, so those hotels may not have the ability to react to individual consumers (Aviv and Pazgal, 2005). Thus, uniform pricing has been evaluated as unrealistic since the hospitality business today is so dynamic that it needs to adjust to changes (Serlen, 2004). Drozdenko and Jensen (2005) advocated that if a company fixes discounts, the products commercialized under a discounted price may be perceived as low quality. On the other hand, consumers might prefer the simplicity of a known, fixed price that is not subject to any changes. Some hotels choose uniform pricing through distribution channels to avoid potential consumer confusion caused by price changes (Choi and Mattila, 2009; Yeaswich, 2004).

Among different pricing strategies, however, both companies and consumers seem to favor dynamic pricing (Dimicco et al., 2003; Kimes, 1989; Sahay, 2007). Dynamic pricing refers to making price changes in a response to marketplace demand that can be implemented in several different ways (Dimicco et al., 2003; Farahmand and Chatterjee, 2008). Dynamic pricing became a popular tool in many industries; this strategy is recognized as profitable for airlines and is practiced in other industries, such as hotels, cruises, and rental cars (Kimes, 1989; 2002; Duman and Mattila, 2003; Sahay, 2007). Not only does dynamic pricing offer greater profits but it also can be used to reallocate demand to more appropriate times and manage a limited supply base (Sahay, 2007). The concept of dynamic pricing helps a firm to sell the right inventory unit to the right consumer at the right time and for the right price (Kimes, 2002).

Figure 1 illustrates that having two prices, compared to having one price, will generate more revenue when fixed and variable costs and the number of consumers remain the same. Beyond the point where the costs have been covered, the potential profits increase as the number of price points increase (Sahay, 2007). Hotels can increase profits through a larger volume of sales. If costs are controlled, then aggressive room pricing can elicit positive results; on the other hand, if low prices fail to cover costs such as maintenance, the long run benefit may be diminished (Enz et al., 2009). Thus, rate reductions must be targeted and differentiated. Since discounts are specifically designed for those who are more price-sensitive, companies do not want to see that consumers willing to pay higher prices take an advantage of discounted prices (Philips, 1981). As consumers perceive the product as an limited offer with special benefits, they may be less price-sensitive; consumers with young children are expected to pay a regular price to stay at a certain hotel due to the uniqueness of 
having a theme park on the property, so then the hotel wouldn't want to offer discounted rate to those particular consumers with young children (Duman and Mattila, 2003). Thus, hotels should segment the market effectively so that lower prices can be used to attract price-sensitive consumers who otherwise wouldn't purchase, while retaining the price-insensitive ones who are willing to pay higher prices.

The largest concern with dynamic pricing is whether consumers accept dynamic pricing as being fair (Kimes, 2002; Sahay, 2007). Consumers' perspectives of the fairness of dynamic pricing depend on the amount of information disclosed to consumers (Choi and Mattila, 2009; Kimes, 2002). Kimes (2002) suggested that a consumer may view a situation as unfair when he or she pays more for a similar service and cannot perceive a difference in the service. If consumers perceive dynamic pricing as unfair, the increased revenues resulting from dynamic pricing may only be short term. However, dynamic pricing should be fairly accepted when information on the different pricing options are made available, including: substantial discounts are given in return for cancellation restrictions; reasonable restrictions are imposed in exchange for a discounted rate; and, different prices are charged for products perceived to be different (Kimes, 2002).

From a consumer's perspective, dynamic pricing enables a consumer to make a choice over the price, so he or she can receive special benefits from accepting restrictions or making reservations in advance. Aviv and Pazgal (2005) studied the optimal pricing of fashion goods, in the presence of strategic and myopic consumers and found that the announced uniform-discount strategies perform essentially the same as contingent pricing policies in the case of myopic consumers. Moreover, Sahay (2007) noted that consumers are more likely to accept dynamic pricing when they are more involved in the pricing process. This finding advocates that consumers enjoy the participation and involvement of the pricing process, so they would respond more to a dynamic pricing than a simple pricing since dynamic pricing requires consumers to be more involved in the pricing processes. Based on the literature discussed above, consumers' reactions toward two different types of pricing, dynamic and uniform pricing, may vary according to the level of involvement in obtaining a discount.

\subsection{Involvement}

In previous studies, the concept of consumer involvement has been widely researched. Zaichkowsky (1985) provided comprehensive concepts of involvement in consumer behavior. Consumers can be involved with advertisements (Murry, Lastovicka and Singh, 1992), products, and purchase decisions (Zaichkowsky, 1985). When consumers appear to be involved in advertising, they are personally affected by advertisements; therefore are motivated to respond to the advertisements. When consumers appear to be involved in products, they are interested in product information based on their needs and values. Thus, when consumers are concerned with receiving a discount, they appear to be involved in obtaining a discount; therefore, consumers will be motivated to make a careful search for deals. While significant impacts are resulted from Involvement on advertising (Gill, Grossbart and Laczniak, 1988; Murry et al., 1992) and information processing (Celsi and Olson, 1988; Park and Hastak, 1994), involvement with purchases has not been studied in great detail in the hospitality industry.

The concept of consumer involvement with purchases leads to be measured based on 
intensity of efforts spent in obtaining a specific activity. High involvement consumers are defined as those who spend more time, effort, and money to search for better deals (Schindler, 1998). Previous literature suggests that involvement could be measured by the time spent in product search, the energy spent, the number of alternatives examined, and the extent of the decision process (Engel and Blackwell, 1982; Schindler, 1998; Stone, 1984). Stone (1984) defined behavioral involvement as time and intensity of effort expended in pursuing a particular activity. Other behavioral alternates for involvement are argued in a leisure context, such as frequency of participation, money spent, miles travelled, ability or skill, ownership of equipment and number of memberships (Kim, Scott and Crompton, 1997). Conversely, low involvement consumers are considered passive toward price deals (Farahmand and Chatterjee, 2008). Low involvement consumers may obtain discount deals when they accidentally encounter them. Some literature indicated that consumers' information search behaviors and purchase decisions could be influenced by demographics, such as a traveler's age and gender (Duman and Mattila, 2003; Fodness and Murray, 1997; Van Raaij and Francken, 1984). In particular, Duman and Mattila (2003) studied roles of demographic variables influencing cruise travelers' discount acceptance and usage behaviors, and indicated that younger and female travelers and travelers with prior experience with cruise vacations were significant predictors of discount usage. Discount receiving behaviors with cruise vacations might be linked with hotel experiences. Thus, the current study examines the role of gender and age in influencing consumers' level of involvement in obtaining a discount, and proposes two hypotheses as follows:

H1: Female consumers are more likely to be involved in obtaining a hotel discount than male consumers

H2: Younger consumers are more likely to be involved in obtaining a hotel discount than older consumers.

In addition, Campo and Yague (2007) analyzed how a purchase at a discount price affects the consumer's perception of price as a function of his or her personal characteristics; they found that individuals with different characteristics perceive the price differently. Varki and Wong (2003) examined the impact of consumer involvement on consumers' willingness to engage in relationships with service providers. Defined as consumers who seek to build a good relationship with service providers, highly involved consumers express a greater interest in engaging in relationships with service providers (Varki and Wong, 2003). Consumers perceive price differently according to individual characteristics (Campo and Yaue, 2007); different people in different situations would lead to various levels of involvement (Houston and Rothschild, 1978). Some studies suggest that frequent consumers who are highly involved and identify with the organization may perceive little need for price discounts and these loyal, committed consumers are likely to enjoy a positive perception of regular prices for the service offered (Beatty, Homer and Kahle, 1988). However, consumers are much more accepting of dynamic pricing when they are more involved in the pricing process. Their participation represents an acceptance of the practice; for example, an auction always has a higher degree of acceptance (Sahay, 2007).

In contrast, uniform pricing strategies perform essentially the same as dynamic pricing policies in the case of low-involved consumers (Aviv and Pazgal, 2008). Thus, higher levels 
of involvement lead to greater levels of consumer loyalty and a lower need for scarce marketing resources. Hence, involvement plays a significant moderating role in the purchase decision; in most cases the relationships are stronger for consumers with higher involvement (Baker et al., 2009; Varki and Wong, 2003). In addition, the degree of involvement that the price promotion is able to generate can cause a large consumer response to a price promotion (Schindler, 1992). According to Schindler (1992)'s study, consumers can become far more involved in a price promotion than any simple consideration of the discount would seem to warrant. From the previous literature, the following hypothesis is proposed:

H3: Consumers highly involved in obtaining a hotel discount respond more positively to dynamic pricing than uniform pricing.

\subsection{Emotional and behavioral responses to pricing}

Traditionally, literature suggests that consumers are interested in price promotions primarily because of the amount of money saved. Weiner (1985) argued that consumers experience pride and positive feelings as a result of attributing positive outcomes to them. Moreover, Kelly's (1967) co-variation theory suggested that the perception of consumers that received a discount not received by everyone else will enhance the "smart-shopper feelings" which result from this discount. Thus, the literature suggests that a consumer's willingness to take restrictions in order to get a discounted rate should lead to a greater achievement and excitement as a form of dynamic pricing. Similarly, consumers will tell more about their purchase and make repeat purchases if they attribute more to the discount's cause (Schindler, 1998). Reynolds and Arnold (2000) pointed out that consumers tend to spread positive word-of mouth and make repeat purchases when they feel they have a good relationship with the service provider. Benefits gained from such a relationship include discounts (Leisen and Prosser, 2004). Therefore, the following hypotheses are proposed in this study:

H4: Consumers highly involved in obtaining a hotel discount experience more positive feelings from a discount, compared to low involvement consumers.

H5: Consumers highly involved in obtaining a hotel discount are more likely to tell others, compared to low involvement consumers.

H6: Consumers highly involved in obtaining a hotel discount are more likely to make repeat purchases, compared to low involvement consumers.

\section{Conceptual research model}

Based on the above discussion, those consumers who are highly involved in obtaining a discount may respond more positively to dynamic pricing than uniform pricing, while experiencing more positive feelings from a discount, be more likely to tell others, and make repeat purchases. As presented in the model shown in Figure 2, the current study categorizes consumers into two groups, based on their level of involvement in obtaining a discount. The two within-subjects variables (high involvement and low involvement) and the between-subjects variable (uniform discount and dynamic discount) were fully crossed, yielding a 2 x 2 design. Both high and low involvement consumers encounter two types of pricing situations, and different reactions may be expected. From the previous studies, consumers who were highly involved in coupon usage resulted in more emotional and behavioral consequence (Schindler, 1998), but those consequences could be both negative 
and positive (Louro, Pieters and Zeelenberg, 2005). Since the current study deals with the impact of discounts, the results are expected to be positive; thus, the study focuses on only positive consequences from obtaining a discount. In the present study, the term "uniform pricing" is narrowly specified as the hotel industry offering a fixed, discounted price. On the other hand, dynamic pricing allows consumers to receive specific benefits if they accept certain restrictions, such as making reservations in advance, a no refund/change policy, or minimum days of stay.

\section{Research Methodology}

\subsection{Measurement}

An experimental study was conducted to examine the impact of pricing strategies on consumers' emotion and behavior with consumers' different levels of involvement. The study was designed by using scenarios. The experimental method relied on Hoch (1988)'s study, which states that respondents tend to use their own feelings and reactions as a guide to evaluating the feelings and reactions of others (Schindler, 1998).

To test hypotheses, t-test and a three-way analysis of variance (ANOVA) were carried out. Means and standard deviations given, ANOVA was used for testing Hypotheses 1 and 2; the groups of gender and age were compared to the mean of two different consumer involvements. Yet a t-test was employed for testing Hypothesis 3 because only high involvement consumers were taken into consideration to compare the means of emotional and behavioral responses between dynamic and uniform pricing. For testing Hypotheses 4, 5, and 6, ANOVA was employed since the data consisted of two different price strategies and two different consumer involvements to compare the means of emotional and behavioral responses. ANOVA put all the data into one number (F) and gave one (P) for the hypotheses thus were appropriate. Hypotheses are often accepted if the p-value is less than 0.05 or 0.01 , corresponding to a $5 \%$ or $1 \%$ chance respectively of rejecting the null hypothesis when it is true. In this study, p-value was considered significant at 0.05 levels (Schindler, 1998; Varki and Wong, 2003).

In this study, split half method was used for checking internal consistency to test the measuring instrument is reliable. Internal consistency was measured with Cronbach's alpha, a statistic calculated from the pair wise correlations between items. An $\alpha$ of 0.79 indicated good reliability. Moreover, the study has demonstrated its validity. Construct validity was established since the variables behave as the study expects them to do (Zikmund, 2003, p.303). To check on the validity of the measure, cross tabulation between involvement and dependant variables were run. The study has an evidence of the construct validity of the measure.

\subsection{Sample}

The proposed research study would utilize a quantitative research method to collect data directly from respondents by measuring their involvement, emotion and behavior intentions. A total of 120 usable surveys were received after twenty responses were eliminated. The convenience sample consisted of respondents who the researcher encountered at Kish Island Airport in a South city in the Iran. The researcher was present at all times, explaining procedures and providing instructions. 


\subsection{Design}

To measure how a respondent reacts differently upon receiving a different discount, the current study adapted the experimental design from Schindler (1998). Table 1 refers to scenarios that were modified from Kimes (2002)'s and Choi and Mattila (2009)'s studies. Each scenario represented a uniform pricing and a dynamic pricing situation. The two within-subjects variables (high-involvement and low-involvement) and the between-subjects variable (uniform discount and dynamic discount) were fully crossed, yielding a $2 \times 2$ experimental design.

For each scenario, five questions, presented in Table 2, were served as dependant variables to each participant regarding how a respondent feels as the protagonist of the scenario and how a respondent responds after having received the discount: good feelings; pride; gratitude; tell others; and, repeat purchase. These variables are adopted from Schindler (1989). Questions concerning good feelings, pride, and gratitude were grouped together to explore emotional responses. In terms of behavioral responses, the likelihood of telling people about the discount and the likelihood of repeat purchase were measured. Each question was answered using a 7 point Likert scale. Although Schindler (1989) used a 9 point scale in his scenarios, Zaichkowsky's (1985) Personal Involvement Inventory (PII) used a 7 point Likert Scale. To keep the scale consistent and to balance it with the data, the scale was switched to a 7 point scale for this study. The scale for the first question, which asks about the participant's good feelings, was anchored at 1 (felt ok, but not especially good) and 7 (felt really good). The scales for the other four questions are anchored at 1 (no) and 7 (yes).

To measure a consumer's involvement of price promotion, Zaichkowsky (1985)'s Personal Involvement Inventory (PII) was employed. PII is a semantic differential scale and offers a comprehensive collection of measurement scales from many different areas of marketing. PII, presented in Table 3, was used to classify respondents into three groups on the basis of their involvement scores, ranged from 20 to 140. Each respondent was asked to judge a scenario given against a 7 point scale according to how they perceive of obtaining a hotel discount. Items on the left are scored (7) being the highest involvement to (1) being the lowest involvement on the right. Some items were scored reverse to make sure respondents read each question carefully, so some items on the left are scored (1) being the lowest involvement to (7) being the highest involvement on the right.

\section{Data Analysis and Results}

\subsection{Profile of respondents}

Based on the study sample of 120 respondents, Table 4 shows the categories of the profile of respondents. The results of demographic profile indicate that the age group of the respondents was evenly distributed between the younger and older group; $45 \%$ belonged to the group of ages below 30 and $55 \%$ to the group of ages 30 years or older. The gender distribution of the respondents was fairly comparable, representing $59 \%$ of male and $41 \%$ of female. The sample size was considered adequate for the number of independent variables involved since 5-10 observations for each independent variable seem to be enough.

The proposed hypothesis was tested using ANOVA. Table 4 refers the means and standard deviations of involvement scores based on gender and age groups. ANOVA of gender 
distribution revealed a significant interaction of involvement (see Table 5). The results revealed that the mean of female group was higher than that of male group at $5 \%$ level of significance $(\mathrm{MF}=116.19$ vs. $\mathrm{MM}=109.38, F=7.186, p<.05)$. The $\mathrm{p}$-value of the t-test $(\mathrm{p}<.05)$ indicated a significant difference in the two means of involvement based on gender. Thus, Hypothesis 1 was supported that female respondents are more likely to be involved in obtaining a discount.

As presented in table 6, ANOVA results of age distribution indicated a significant interaction of involvement with age. The results indicated that the mean of "younger than 30 years old" was higher than the older group at $5 \%$ level of significance $(\mathrm{MY}=115.1$ vs. $\mathrm{MO}=109.52$, $F=4.952, p<.05)$. Therefore, Hypothesis 2 was supported that younger respondents are significantly more involved in obtaining a hotel discount.

Zaichkowsky's PII was used to classify respondents into three groups on the basis of their involvement scores (Zaichkowsky, 1985; Varki and Wong, 2003). From 120 involvement scores, which ranged from 20 to 140 , the top forty responses were classified as high involvement consumers and the bottom forty as low involvement consumers, with the middle forty excluded. Based on the distribution of scores in the range of 20 to 140, involvement scores between 20 and 104 were categorized as low involvement and scores between 127 and 140 were categorized as high involvement.

To examine consumers who are highly involved in obtaining a discount respond more positively to dynamic pricing than uniform pricing, only forty responses from those classified as high involvement consumers in the sample were included. Therefore, the number of responses amounted to 80 with 40 from the dynamic pricing group and 40 from the uniform pricing group. Then, five dependent variables were measured to see how high involvement consumers reported to dynamic and uniform pricing. Dependent variables concerning good feelings, pride, and gratitude were grouped together to explore emotional responses. Dynamic and uniform pricing strategies served as independent variables and emotional and behavioral response scores served as dependent variables.

Table 7 refers to the means and standard deviations of emotional and behavioral scores based on price strategies, and Table 8 to ANOVA results. In the presence of highly involved consumers, the mean of dynamic pricing for emotional scores was

Higher than the mean of uniform pricing at $0.1 \%$ level of significance $(\mathrm{ME}$, Dynamic $=5.72$ vs. ME, Uniform $=2.98, p<.001)$. In addition, the mean of dynamic pricing for "tell others" was higher than the mean of uniform pricing at $0.1 \%$ level of significance (MT, Dynamic $=6.32$ vs. MT, Uniform $=3.24, p<.001$ ). Similarly, the mean of dynamic pricing for repeat purchase scores was noticeably higher compared to the mean of uniform pricing at $0.1 \%$ level of significance $(\mathrm{MR}$, Dynamic $=7.94 \mathrm{vs.} \mathrm{MR}$, Uniform $=3.81$, $p<.001)$. Therefore, Hypothesis 3 was supported.

With regard to Hypothesis 4, the two levels of consumers' involvement in obtaining a discount served as independent variables and emotional response served as dependent variable. To evaluate their positive feelings toward a discount, respondents were asked three questions: good feelings; pride; and, gratitude. Measuring consumers' emotional responses, an average of three scores was taken to run ANOVA. Table 9 refers to the means and standard 
deviations of emotional and behavioral scores based on levels of involvement. The results of ANOVA, presented in Table 10, indicated a significant effect that consumers highly involved in obtaining a hotel discount experienced more positive feelings from a discount. Positive emotion measures were considerably affected by its involvement. The obtained results revealed that the mean of emotional scores for high involvement consumers were higher than the one for low involvement consumers at $5 \%$ level of significance (ME, Low $=4.08$ vs. ME, High $=5.14, F=8.122, p<.05)$. It appeared to have a significant interaction between the levels of involvement and positive feelings. Thus, Hypothesis 4 was supported: Consumers highly involved in obtaining a discount show more positive feelings from a discount.

Moreover, the mean of variable "tell others" scores for high involvement consumers were founded to be higher than the one for low involvement consumers at $5 \%$ level of significance $(\mathrm{MT}$, Low $=4.35$ vs. MT, High= 4.88, $F=6.615, p<.05)$. Likewise, the mean of repeat purchase scores for high involvement consumers were higher than the one for low involvement consumers at $5 \%$ level of significance $(\mathrm{MR}$, Low $=4.99$ vs. MR, High= 5.66, $F=5.832, p<.05$ ). Therefore, the results of ANOVA supported Hypotheses 5 and 6 that consumers highly involved in obtaining a discount are more likely to tell others and to make repeat purchases. A positive interaction between the levels of involvement and the likelihood of telling others and repeat purchases was found.

\section{Conclusion}

Given today's economic situation, firms are encouraged to use pricing strategies effectively to influence consumers, and online environment enables firms to dynamically manage prices. However, pricing decisions should be made with a careful understanding of their impact on consumers' responses (Choi and Mattila, 2009) because pricing mistakes can harm firms much more heavily in a downturn than in an upturn.

Moreover, literature suggested that individuals with different characteristics perceive the price differently (Campo and Yague, 2007), and individual consumers show different reactions to price of the same product in different situations, channels, and occasions of use (Kimes, 2002). While past literature indicated that demographics, such as traveler's age, income, education, gender, and the number and composition of the traveling group, influence consumers' information search behaviors and purchase decisions (Duman and Mattila, 2003), the current study also examined the role of gender and age in influencing consumers' level of involvement in obtaining a discount. The results of ANOVA indicated that female and younger consumers are more involved in obtaining a discount. The fundamental purpose of this study is to investigate how consumers' emotion and behavior are influenced by uniform pricing and dynamic pricing, in the presence of high involvement consumers. The results of the study indicate that consumers highly involved in obtaining a discount respond more positively to dynamic pricing than uniform pricing.

Moreover, literature suggested that price promotion have not only monetary benefits but also emotional achievements beyond the economic value of the money saved (Schindler, 1989). Researchers note that price promotions have an ability to bring out strong feelings such as pride and anger when feelings are considered important in human motivation (Bandura 1977; Schindler, 1989). Purchase intentions will increase when consumers perceive themselves paying a good price for the benefits obtained (Ingenbleek, 2007; Noonen and Mount, 2007). 
In an effort to understand consumers' emotions and behaviors of obtaining a discount, this study explores such influences of different levels of involvement on consumer reactions. The results of the study indicate a significant interaction between the levels of consumers' involvement in obtaining a discount and the levels of emotional and behavioral reactions. As compare to low involvement consumers, high involvement consumers significantly showed more positive feelings from a discount, and were more likely to tell others and to make repeat purchases.

The theoretical contributions of this study have been carefully presented. Researchers have developed numerous theories related to the concept of consumer involvement in an attempt to explain and predict the behavior of the consumer (Baker et al., 2009; Varki and Wong, 2003; Zaichkowsky, 1985). However, there have been limited studies done to link involvement and pricing in terms of discounts. Thus, this study has attempted to examine differential involvements a consumer may attribute to a discount affecting consumers' preferences on price strategies. It has been worthwhile to study this linkage because hotels heavily rely on discounts due to the economic recession and are becoming increasingly interested in discounts.

This study has also suggested an understanding of emotional and behavioral responses with differential levels of involvement. While literature suggests that consumers are interested in price promotions primarily because of the amount of money saved (Ashworth, Darke, \& Schaller, 2005), studies recommend that understanding a consumer's value perceptions such as satisfaction, pride, and positive feelings, is critical (Weiner, 1985; Ingenbleek, 2007; Noone and Mount, 2007). Although the motivational factors underlying price promotions have not been considered to be as important in the literature, recently, consumers' emotions have recently gained more attention.

This research has several practical implications for hotel managers. First, hotel managers may consider offering various discounts aimed at younger and female travelers. Second, hotel managers are advised to identify dynamic pricing to attract their high involvement consumers. Third, discounts seem to attract high involvement consumers more effectively than low involvement consumers. According to the results of this study, high involvement consumers are more likely to show positive emotions, tell others, and make repeat purchases. Lastly, taken together, the findings of this study recommend hotel managers to segment consumers into differential involvement groups. Hotel managers may possibly design price promotions targeting a specific group. Also, managers are advised to take a caution when introducing a new price promotion.

Limitations and future studies are discussed as follows. First, this study was conducted based on scenarios, and this method solely relies on the tendency for respondents to use their own feelings and reactions as a guide to judging the feelings and reactions of others (Hoch, 1988). Respondents may be exposed to the bias of human nature. Also the interpersonal dynamics associated with service encounters should be excluded. Second, ages of respondents were regrouped into two categories to simplify the data analysis and interpretation, although there were more than two categories in the research instrument. Third, the participants in the present study evaluated hotel prices for a single location. Some respondents might thus lack a 
realistic understanding of appropriate price ranges for room rates. The size of discount might be considered as too small or too big. Future research can explore the role of the size of price differences. In this study, two prices of the hotel adopting the differential pricing policy varied by $10 \%$. In addition, while both companies and consumers are apt to favor dynamic pricing, dynamic pricing may not be appropriate in other industries, especially where fixed cost is low and variable cost is high. Finally, a better understanding of the role of consumer involvement on price strategies is in acute need. Future study is therefore needed to better understanding the role of involvement on prices on consumer perceptions of variable price strategies. Future studies should incorporate additional variables that are not considered in the present study such as family size or previous experience.

\section{References}

Aviv, Y., \& Pazgal, A. (2005). Optimal pricing of seasonal products in the presence of forward-looking consumers. Working paper, Washington University.

Baker, T., Cronin, J., \& Hopkins, C. (2009). The impact of involvement on key service relationships. Journal of Services Marketing, 23(2), 115-124. http://dx.doi.org/10.1108/08876040910946378

Campo, S., \& Yague, M. (2007). The perception of price discounts according to consumer's characteristics. Journal of Revenue and Pricing Management, 6(2), 86-99. http://dx.doi.org/10.1057/palgrave.rpm.5160068

Coulter, K. S. (2001). Decreasing price sensitivity involving physical product inventory: A yield management application. The Journal of Product and Brand Management, 10(4/5), 301-317. http://dx.doi.org/10.1108/EUM0000000005846

Dimicco, J. M., Maes, P., \& Greenwald, A. (2003). Learning curve: A simulation-based approach to dynamic pricing. Electronic Commerce Research, 3(3/4), 245-276. http://dx.doi.org/10.1023/A:1023427023289

Duman, T., \& Mattila, A. (2003). A logistic regression analysis of discount receiving behavior in the cruise industry: Implications for cruise marketers. International Journal of Hospitality \& Tourism Administration, 4(4), 45-57. http://dx.doi.org/10.1300/J149v04n04_03

Eisen, D. (2006, January 19). Buyers Resist Dynamic Hotel Pricing Tide. BTNonline.com. Retrieved from http://www.btnonline.com/businesstravelnews/headlines

Farahmand, A., \& Chatterjee, C. (2008). The case for dynamic pricing. Hospitality Upgrade, 154-155.

Fodness, D., \& Murray, B. (1997). Tourist information search. Annals of Tourism Research, 24(3), 503-523. http://dx.doi.org/10.1016/S0160-7383(97)00009-1

Hoch, S. J. (1988). Who do we know Predicting the interests and opinions of the American consumer. Journal of Consumer Research, 15, 315-324. http://dx.doi.org/10.1086/209169

Kelly, H. H. (1967). Attribution theory in social psychology. In D. Levine (Ed.), Nebraska 
Symposium on Motivation (pp. 192-238). Lincoln: University of Nebraska Press.

Kick, Fran. (2005). What makes kids kick: Inspiring the millennial generation to kick it. Instruction \& Design Concepts. pp. 33.

Kimes, S. E. (1989). The basics of yield management. Cornell Hotel and Restaurant Administration Quarterly, 30(14), 14-19. http://dx.doi.org/10.1177/001088048903000309

Leisen, B., \& Prosser, E. (2004). Customers' perception of expensiveness and its impact on loyalty behaviors. Services Marketing Quarterly, 25(3), 35-52. http://dx.doi.org/10.1300/J396v25n03_03

Normand, Perry-Soulanges. (2010, February 17). La génération «Y » et la sphère politique au Québec. [The generation Y of the political sphere in Quebec].

Raaij, W., \& Francken, D. (1984). Vacation decisions, activities and satisfactions. Annals of Tourism Research, 11(1), 101-112. http://dx.doi.org/10.1016/0160-7383(84)90098-7

Reynolds, K. E., \& Arnold, M. J. (2000). Customer loyalty to the salesperson and the store: Examining relationship customers in an upscale retail context. The Journal of Personal Selling \& Sales Management, 20(2), 89-98.

Sahay, A. (2007). How to reap higher profits with dynamic pricing. MIT Sloan Management Review, 48, 53-60.

Schindler, R. M. (1989). The excitement of getting a bargain: Some Hypotheses concerning the origins and effects of smart-shopper feelings. Advances in Consumer Research, 16(1), 447-453.

Schindler, R. M. (1992). A coupon is more than a low price: Evidence from a shopping$\begin{array}{lllll}\text { simulation study. Psychology \& } \quad \text { Marketing, } & 9(6), & 431 .\end{array}$ http://dx.doi.org/10.1002/mar.4220090603

Schindler, R. M. (1998). Consequences of perceiving oneself as responsible for obtaining a discount: Evidence for smart-shopper feelings. Journal of Consumer Psychology, 7(4), 371-392. http://dx.doi.org/10.1207/s15327663jcp0704_04

Serlen, B. (2004, June 19). Hotel Rates Go Dynamic. BTNonline.com. Retrieved from http://www.btnonline.com/businesstravelnews

Varki, S., \& Wong, S. (2003). Consumer involvement in relationship marketing of services. Journal of Service Research, 6(1), 83. http://dx.doi.org/10.1177/1094670503254287

Wakefield, K. L., \& Bush, V. D. (1998). Promoting leisure services: Economic and emotional aspects of consumer response. The Journal of Services Marketing, 12(3), 209. http://dx.doi.org/10.1108/08876049810219520

Weiner, B. (1985). An attributional theory of achievement motivation and emotion. Psychological Review, 92(4), 548-573. http://dx.doi.org/10.1037/0033-295X.92.4.548

Woodworth, M. R. (2009). Falling industry profits. Cornell Hospitality Quarterly, 50, 15. 


\section{Macrothink}

http://dx.doi.org/10.1177/1938965508330317

Yesawich, P. C. (2004). Consistent pricing will give consumers booking confidence. Hotel and Motel Management, 219(4), 18.

Zaichkowsky, J. L. (1985). Measuring the involvement construct. Journal of Consumer Research, 12, 341-52. http://dx.doi.org/10.1086/208520

Zikmund, W. G. (2003). Business Research Methods, $7^{\text {th }}$ ed. pp. 301-382.
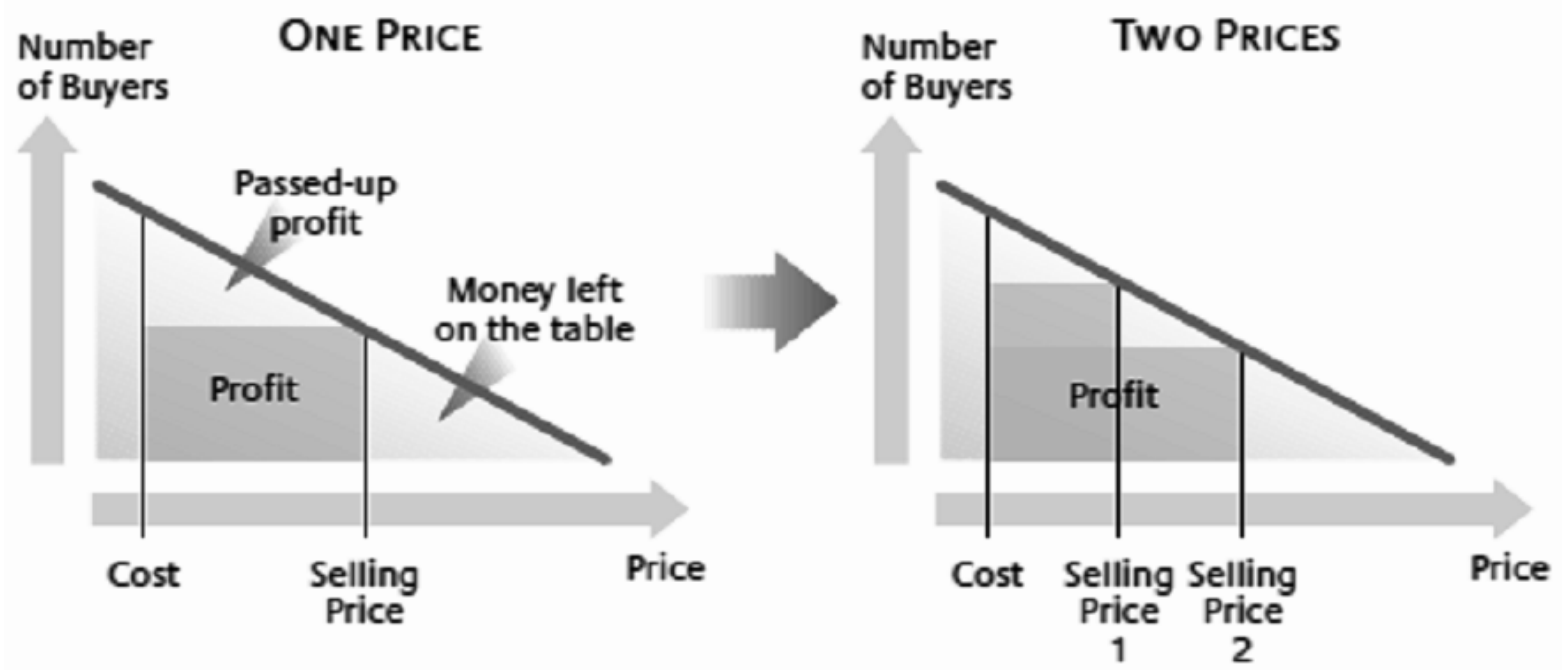

Figure 1. Effectiveness of dynamic pricing. Adapted from "How to Reap Higher Profits with Dynamic Pricing," by A. Sahay, 2007, MIT Sloan Management Review, 48, p. 53-60.

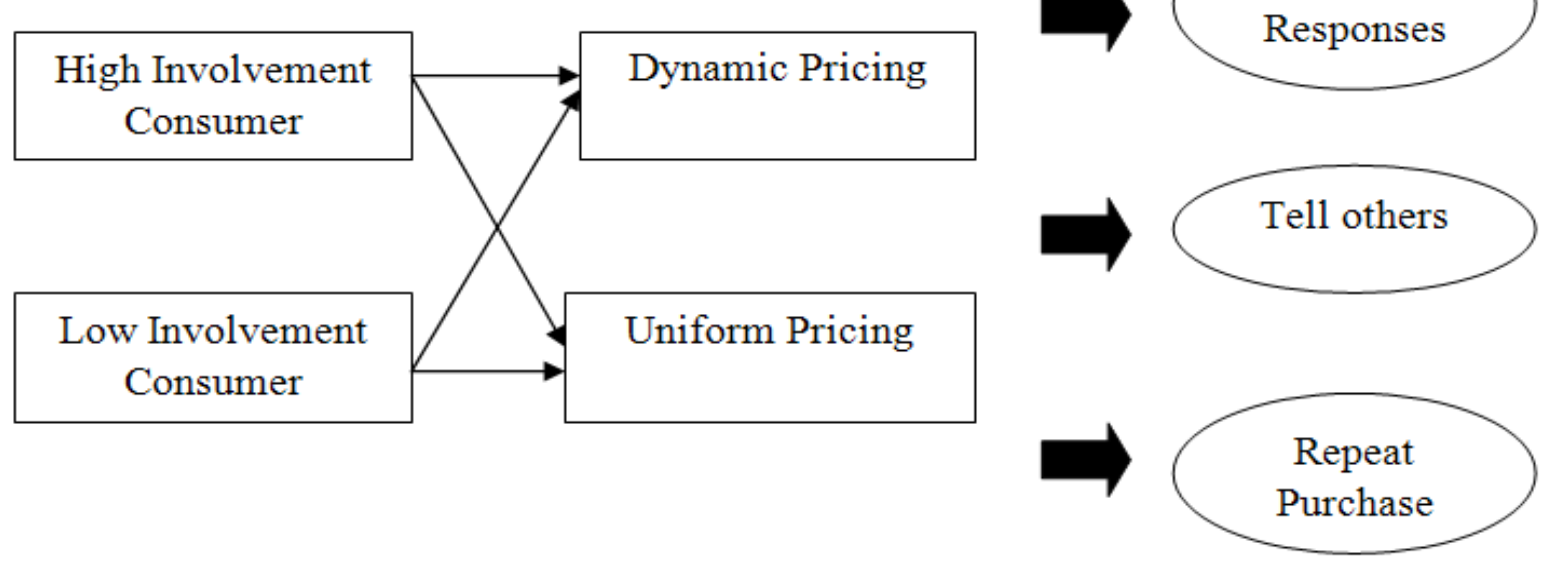

Figure 2. Perceptions of receiving a hotel discount. 
Table 1. Senarios

\begin{tabular}{|l|l|}
\hline \multicolumn{1}{|c|}{ Uniform Scenario } & \multicolumn{1}{|c|}{ Dynamic Scenario } \\
\hline $\begin{array}{l}\text { Imagine that you need to travel to Kish } \\
\text { Island for leisure purpose. You want to book } \\
\text { one standard room with a king-size bed in a } \\
\text { mid priced hotel for one night. You found a } \\
\text { hotel that advertises a special rate of } 10 \% \\
\text { cheaper than its rack rate. You made a } \\
\text { reservation right away. }\end{array}$ & $\begin{array}{l}\text { Island for leisure purpose. You booked one } \\
\text { standard room with a king-size bed in a mid } \\
\text { priced hotel for one night. You start having } \\
\text { a conversation with someone who is sitting } \\
\text { next to you in the restaurant. You room is } \\
\text { identical to his or hers, and the rooms are } \\
\text { next to one another. It seems that the person } \\
\text { paid \$100 for a room, but you paid only } \\
\$ 80 . \text { You made a reservation 30 days before } \\
\text { arrival, and he or she made a reservation the } \\
\text { day before. }\end{array}$ \\
\hline
\end{tabular}

Table 2. Measurement of Emotional and Behavioral Responses (R. M. Schindler, 1998)

\begin{tabular}{|c|c|c|}
\hline \multicolumn{2}{|c|}{ Variable } & Question \\
\hline \multirow{3}{*}{$\begin{array}{l}\text { Emotional } \\
\text { Responses }\end{array}$} & Good feelings & $\begin{array}{l}\text { How good would you feel about } \\
\text { receiving a discount? }\end{array}$ \\
\hline & Pride & $\begin{array}{l}\text { Would you feel proud that you } \\
\text { received a discount? }\end{array}$ \\
\hline & Gratitude & $\begin{array}{l}\text { Would you feel gratitude to the hotel } \\
\text { for offering a discount? }\end{array}$ \\
\hline \multicolumn{2}{|c|}{ Tell others } & $\begin{array}{l}\text { Would you tell a lot of people that you } \\
\text { received a discount? }\end{array}$ \\
\hline \multicolumn{2}{|c|}{ Repeat purchase } & $\begin{array}{l}\text { Would you go to that hotel again the } \\
\text { next time you are looking for a room? }\end{array}$ \\
\hline
\end{tabular}


Table 3. Personal Involvement Inventory (J. L. Zaichkowsky, 1985)

\begin{tabular}{|c|c|}
\hline High involvement & Low involvement \\
\hline Important & Unimportant \\
\hline Relevant & Irrelevant \\
\hline Means a lot to me & Means nothing to me \\
\hline Valuable & Worthless \\
\hline Interesting & Boring \\
\hline Appealing & Unappealing \\
\hline Needed & Not needed \\
\hline Of concern to me & Of no concern to me \\
\hline Useful & Useless \\
\hline Fundamental & Trivial \\
\hline Beneficial & Not beneficial \\
\hline Matters to me & Doesn't matter \\
\hline Interested & Uninterested \\
\hline Significant & Insignificant \\
\hline Vital & Superfluous \\
\hline Exciting & Unexciting \\
\hline Fascinating & Mundane \\
\hline Essential & Nonessential \\
\hline Desirable & Undesirable \\
\hline Wanted & Unwanted \\
\hline
\end{tabular}

Table 4. Means of Gender and Age Groups

\begin{tabular}{|c|c|c|c|}
\hline Involvement & Mean & $\mathbf{N}$ & SD \\
\hline \multicolumn{4}{|l|}{ Gender } \\
\hline Male & 109.38 & 141 & 23.1 \\
\hline Female & 116.19 & 99 & 24.98 \\
\hline \multicolumn{4}{|l|}{ Age } \\
\hline Younger & 115.1 & 108 & 19.57 \\
\hline Older & 109.52 & 132 & 26.85 \\
\hline Total & 115.68 & 240 & 25.73 \\
\hline
\end{tabular}


Table 5. Analysis of Variance for Involvement Based on Gender

\begin{tabular}{|c|c|c|c|c|}
\hline Source of Involvement & $\underline{\text { dff }}$ & $\mathbf{F}$ & MS & $\mathbf{P}$ \\
\hline Gender & 1 & $7.186^{*}$ & 4102.124 & 0.004 \\
\hline
\end{tabular}

Note. ${ }^{*} \mathrm{p}<0.05$.

Table 6. Analysis of Variance for Involvement Based on Age

\begin{tabular}{|c|c|c|c|c|}
\hline Source of Involvement & df & $\mathbf{F}$ & MS & $\mathbf{P}$ \\
\hline Age & 1 & $4.952 *$ & 2985.254 & 0.02 \\
\hline
\end{tabular}

Note. ${ }^{*} \mathrm{p}<0.05$.

Table 7. Means of Variables in Uniform and Dynamic Pricings

\begin{tabular}{|c|c|c|c|c|}
\hline \multirow{2}{*}{ Variables } & \multicolumn{2}{|c|}{ Uniform } & \multicolumn{2}{c|}{ Dynamic } \\
\cline { 2 - 5 } & $\mathrm{M}$ & $\mathrm{SD}$ & $\mathrm{M}$ & $\mathrm{SD}$ \\
\hline Emotional Responses & 2.98 & 1.68 & 5.72 & 0.95 \\
\hline Tell Others & 3.24 & 2.36 & 6.32 & 1.13 \\
\hline Repeat Purchase & 3.81 & 2.5 & 7.94 & 1.96 \\
\hline
\end{tabular}

Table 8. Dependent Variables for High Involvement Consumers

\begin{tabular}{|c|c|c|c|c|}
\hline \multirow{2}{*}{ Variables } & \multicolumn{2}{|c|}{ Price Strategies } & \multirow{2}{*}{$\mathrm{t}$} & \multirow{2}{*}{ df } \\
\cline { 2 - 3 } & Uniform & Dynamic & & \\
\hline Emotional Responses & 2.98 & 5.72 & $7.54^{*}$ & 78 \\
\hline Tell Others & 3.24 & 6.32 & $5.65^{*}$ & 78 \\
\hline Repeat Purchase & 3.81 & 7.94 & $6.32^{*}$ & 78 \\
\hline
\end{tabular}

Note. ${ }^{*} \mathrm{p}<.001$. Standard Deviations appear in parentheses below means.

Table 9. Means of Variables in Low and High Involvement Consumer Groups

\begin{tabular}{|c|c|c|c|c|}
\hline \multirow{2}{*}{ Variables } & \multicolumn{2}{|c|}{ Low } & \multicolumn{2}{c|}{ High } \\
\cline { 2 - 5 } & $\mathrm{M}$ & $\mathrm{SD}$ & $\mathrm{M}$ & $\mathrm{SD}$ \\
\hline Emotional Responses & 4.08 & 1.61 & 5.14 & 2.1 \\
\hline Tell Others & 4.35 & 1.89 & 4.88 & 2.02 \\
\hline Repeat Purchase & 4.99 & 1.65 & 5.66 & 2.39 \\
\hline
\end{tabular}

Table 10. Analysis of Variance for Variables Based on Involvement

\begin{tabular}{|c|c|c|c|c|}
\hline Involvement & df & F & MS & P \\
\hline Emotional Responses & 1 & $8.122^{*}$ & 38.000 & 0.007 \\
\hline Tell Others & 1 & $6.615^{*}$ & 27.011 & 0.005 \\
\hline Repeat Purchase & 1 & $5.832^{*}$ & 20.458 & 0.028 \\
\hline
\end{tabular}

Note. ${ }^{*} \mathrm{p}<0.05$. Standard Deviations appear in parentheses below means. 